\title{
Revista
}

\section{A ESCOLA E O ESTADO COMO FORMADOR DE VIOLÊNCIA E VIOLÊNCIA SIMBÓLICA DURANTE O ESTADO NOVO NO PARANÁ}

\author{
SCHOOL AND THE STATE AS TRAINER OF VIOLENCE AND SYMBOLIC VIOLENCE \\ DURING THE SO CALLED NEW STATE IN PARANÁ
}

Talita Cristine Rugeri $^{1}$

\begin{abstract}
RESUMO
Pesquisa realizada por meio do projeto PIBIC/PUCPR em 2010 com cruzamento de dados referentes de como o Estado através da escola agiu com violência e violência simbólica em relação à etnia alemã e seus descendentes. Tendo como objetivo perceber como as escolas étnicas alemãs mantinham a identidade através da língua vernácula; perpetuavam sua cultura e o sentimento nacional de origem; sendo que essas escolas foram alvo da política de nacionalização do Estado Novo que tinha como objetivo nacionalizar todos os imigrantes e descendentes através da obrigatoriedade do uso exclusivo da língua portuguesa através da proibição da língua de origem, exaltando a cultura nacional brasileira e da imagem de Getúlio Vargas. Através de análises de fontes bibliográficas sobre a etnia alemã, nacionalização, Estado Novo, etnicidade, relações de poder e violência simbólica como Max Weber (1982), Pierre Bourdieu (2010), Getulio Vargas (1943), Relatórios de Governo de 1932 a 1949, Arquivos da Delegacia de Ordem Política e Social (1930 a 1940), entrevistas com alemães e descendentes que vivenciaram ou relataram vivências durante o período de nacionalização compulsória; conclui-se que uma política de Estado ditatorial utilizando as escolas, a inspeção escolar agiu com violência e poder simbólico. Forçando a inclusão a cultura local e através de poder legal e tradicional tenta quebrar signos culturais de origem impondo uma nova ordem educacional e sócio-cultural.
\end{abstract}

Palavras-chave: Escolas étnicas. Nacionalização. Violência simbólica.

\begin{abstract}
Research conducted by the project PIBIC / PUCPR 2010 with crossing data regarding how the State through school acted with violence and symbolic violence against ethnic Germans and their descendants. Aiming to understand how schools kept the ethnic German identity through vernacular; perpetuated their culture and sense of national origin, and these schools target the nationalization policy of the Estado Novo that aimed to nationalize all immigrants and descendants through mandatory the exclusive use of the Portuguese language, the prohibition of the source language, extolling the Brazilian national culture and image of Getúlio Vargas. Through analysis of literature sources on the German ethnicity, nationalization, Estado Novo, ethnicity, power relations and symbolic violence as Max Weber (1982), Pierre Bourdieu (2010), Getulio Vargas (1943), Reports of Government 1932-1949 , Archives of the Bureau of political and Social Order (1930-1940), German and interviews with descendants who experienced or reported livings during the compulsory nationalization, it is concluded that a policy of using dictatorial state schools, the school inspection acted violence and symbolic power. Forcing the inclusion of local culture and through legal power and tries to break traditional cultural signs of origin imposing a new order educational and socio-cultural.
\end{abstract}

Keywords: Ethnic schools. Nationalization. Symbolic violence.

\footnotetext{
${ }^{1}$ Mestranda em Sociologia da Educação pelo Programa de Pós-graduação da PUCPR. talitarugeri@gmail.com
} 


\section{INTRODUÇÃO}

$\mathbf{P}$

\section{olíticas Migratórias}

Desde o fim do Império e começo da Republica existem políticas de imigração para o

Brasil. Com caráter primordialmente econômico, a vinda de imigrantes reconfigura o cenário nacional. No período de 1829 a 1911 entraram no Estado do Paraná aproximadamente 100 mil imigrantes dispersados pelas cem colônias fundadas no estado (TEIXEIRA, 2008). Entre varias etnias vindas, a etnia abordada nesta pesquisa é a etnia alemã.

O período de livre expansão da etnia alemã no Sul do Brasil durou até o ano de 1937, inclusive. Tal como ocorreram nos demais estados sulinos, também no Paraná o teuto brasileiro havia se propagado e consolidado apreciavelmente as suas posições, alcançando naquele ano um apogeu jamais pensado. (ABECK, 1980, p.23)

Os alemães estabeleceram suas colônias no estado no Paraná, em cidades como Curitiba com as colônias Lamenha, Riviére; Ponta Grossa com a colônia Otavio; Lapa com Virmond; também na cidade de Palmeira, com a colônia Santa Barbara; Rio Negro, com as colônias Augusta, Vitória e Lucena; Prudentópolis, com a colônia Prudentópolis; Irati, com a colônia Irati; Guarapuava com a colônia Cruz Machado; Cambé, com a colônia Vila Nova Dantzig; e Rolândia, com a colônia Gleba Roland. Sendo essas cidades as primeiras a receberem imigrantes alemães que chegaram nesses locais e exerciam as mesmas atividades do país de origem, como forma de organização social, de trabalho, religião e também de ensino escolar. Dessa maneira, influenciaram o desenvolvimento local através da arquitetura, alimentação, religião, ensino, agricultura e posteriormente no setor industrial.

A língua falada entre as comunidades alemãs continuava sendo o alemão, e em alguns casos dialetos, pois a língua possibilitava criar um sentido ao local para essas pessoas que vieram de um país distante, podendo assim perpetuar o sentimento de etnia alemã que passa de fronteiras geográficas, fortalecendo a cultura de origem.

Uma das maneiras de manter a cultura de origem era através da língua nas escolas e colônias que lecionassem em alemão e em algumas bilíngües. Com uma tradição de ensino vinda da Alemanha possibilitava que a língua e a cultura alemã permanecessem nos padrões de origem; já que na Alemanha as escolas eram tradicionais, construídas e mantidas pelo Estado Alemão.

No Brasil o numero de escolas étnicas alemãs segundo Kreutz (2000) e Ando (1996) era de 1.579; essas escolas eram independentes com organização e práticas pedagógicas próprias, pois havia poucas escolas públicas.

Portanto, essas escolas foram alvo das políticas nacionalistas que se formaram desde o inicio da República no Brasil e tiveram o seu ápice durante o período de Estado Novo (1937-1945) 
implementado por Getúlio Vargas. Essas políticas tinham cunho de criar uma identidade nacional brasileira principalmente através da educação em língua portuguesa; e essas comunidades étnicas, especificamente nessa pesquisa os alemães, tinham que se integrar à nação brasileira, através da cultura, do sentimento nacional e, principalmente, da língua nacional.

De que maneira essa política nacionalista do Estado Novo age com violência, violência simbólica e poder simbólico nas escolas perante esses alemães e seus descendentes que aqui estavam?

Para responder a essa questão foram analisadas fontes bibliográficas sobre os alemães no Estado no Paraná; como se organizavam, especialmente em relação às escolas nas colônias; bibliografias como as diretrizes de governo de Getulio Vargas; Primeiro Centenário de Governo da Emancipação Política do Paraná; teorias sobre etnia e etnicidade, que contribuíram para a compreensão da criação de identidade, sentimento e pertencimento a um grupo. Tendo como base as teorias de Max Weber (1982) em suas análises sobre relações entre poder e dominação, Pierre Bourdieu (2010), criador do termo poder e violência simbólica, que fornece embasamento para a formulação da pesquisa. As fontes primárias documentais utilizadas são os Relatórios de Governo do Estado do Paraná no Arquivo Público de Curitiba, relatos arquivados de imigrantes e descendentes, entrevistas com alemães e seus descendentes que viveram durante o período do Estado Novo.

Entrevistou-se quatro descendentes HPS, LK, CH, AF que contribuíram para a formulação da pesquisa pelas vivências e relatos fornecidos. Três com mais de 80 anos que relatam a relação do aprendizado do português na escola, e em casa falavam apenas o alemão; e uma entrevistada que relata a experiência pessoal e de seu pai.

Analisando as fontes e as entrevistas é possível compreender o Estado agindo como violência e violência simbólica através da educação em que as escolas se tornaram o meio para atingir o fim desejado: a nacionalização dos imigrantes e descendentes.

\section{A EDUCAÇÃO NAS COLÔNIAS ALEMÃS E O PROCESSO DE NACIONALIZAÇÃO}

Nas colônias alemãs havia escolas étnicas e em alguns casos o ensino também acontecia em clubes e às vezes em igrejas, como o caso do Colégio Erasto Gaertner, localizado no bairro Boqueirão na cidade de Curitiba que durante a semana funcionava como escola e aos finais de semana como Igreja Menonita.

A língua é a estrutura de conhecimento fundamental na construção de universos e simbologias, dando sentido ao local, comunidade e nação. A função de comunicação proporciona às 
nações de interagirem suas culturas através da língua e também de perpetuarem por gerações sua cultura.

Tanto em comunidades alemãs protestantes, mas também com alemães católicos, batistas e menonitas - que fundaram escolas em Curitiba como Bom Jesus, Erasto Gaertner, Deutsche Schule - criaram formas de lecionarem em língua alemã.

Percebe-se que a etnicidade, abordado por Phiippe Putignat e Jocelyne Streiff-Fenartpo (1998), nas comunidades alemãs, a percepção de pertencer a um grupo através da língua é perceptível; consideram-se membros de uma sociedade mesmo morando em outra localidade. O sentimento do grupo pela sua cultura, intensificado pela língua, passa das fronteiras nacionais que muitas vezes se fortalecem para prevalecer à identidade.

Essa característica da etnicidade percebida nas comunidades alemãs no Paraná, principalmente mantidas pelas escolas, demonstra a identificação do eu com o outro, ou seja, perceber-se dentro de um grupo étnico, independente de sexo, idade, classe social e até mesmo religião. Tanto alemães menonitas, católicos e protestantes tinham interesse da existência de uma escola que mantivesse a tradição de origem, pois partilham um mesmo sentimento. Grupos que estão distantes de sua terra de origem, convivendo em um local com costumes, trabalho, língua diferente e, principalmente, o que foi relatado em entrevistas, a dificuldade de adaptação e o sofrimento social, econômico e cultural que passavam faz com que a identidade se fortaleça através da língua. Portanto, a manutenção de um sentimento nacional de origem proporcionava um conforto entre as famílias alemãs, mantendo assim suas tradições.

Durante o Estado Novo de Getulio Vargas (1937-1945), a campanha de nacionalização tinha o intuito de acabar com essas comunidades estrangeiras no Brasil, forçando a integração à população brasileira, através da cultura, da imprensa, da língua para a criação de um sentimento nacional por toda a população brasileira e estrangeira que aqui estava.

Com o grande numero de imigrantes em nosso país, Getulio Vargas relata que a política imigratória é apenas para cobrir aspectos econômicos imediatos e que deve ocorrer uma seleção das etnias para a entrada no Brasil. O imigrante deve vir para ajudar no progresso e nunca promover a desordem, aceitando nossas leis, enfatizando que somos donos de nossas terras. (VARGAS, 1943). Sendo que para Vargas o imigrante de maior importância para a formação de nosso país seria o português, que para Vargas além de útil, integraria suas tradições e a língua.

O Estado Novo, na campanha de nacionalização, caracterizou-se pelo predomínio do Poder Executivo sobre o Legislativo, fortalecendo departamento administrativo, polícia secreta, controles sindicais, entre várias outras mudanças políticas sociais e econômicas. Em seu livro “As diretrizes da nova política do Brasil”, Vargas (1943) relata todo seu plano de governo, inclusive sobre a 
política demográfica; ele ressalta a importância da uniformização demográfica do país através da língua, da cultura e da educação. Relata, também, a relação do estrangeiro no Brasil, sempre focando a soberania nacional.

\begin{abstract}
A revisão das leis de estrangeiros orientou-se pelos seguintes princípios: a) garantir o cumprimento dos dispositivos, no interesse da soberania e da segurança nacional, limitando o exercício dos direitos políticos dos estrangeiros ou brasileiros naturalizados; b) promover a assimilação mais rápida dos estrangeiros e facilitar os meios de nacionalizar os seus descendentes; c) impedir a formação de núcleos inassimiláveis e compactos de estrangeiros; d) evitar a entrada e permanência de elementos turbulentos ou perigosos à ordem pública ou à segurança do Estado; e) policiar as atividades dos elementos alienígenas, impedindo que se tornem nocivos aos interesses do Estado. Os decretos-leis ns. 383, 389, 394, 406, 479, 554 e 639 consubstanciam as disposições necessárias dos bons cumprimentos dos dispositivos indicados. ( VARGAS, 1943, p. 283)
\end{abstract}

Nesta citação, percebe-se o caráter político autoritário de Vargas perante os imigrantes, principalmente por propor em acabar com os núcleos estrangeiros que já existiam, e impedir a formação de novos núcleos inassimiláveis e compactos. E a limitação das ações políticas dos estrangeiros no Brasil, já que esses núcleos não falavam português e não interagiam na cultura brasileira. Nas comunidades étnicas a maioria das crianças frequentava a escola étnica e eram alfabetizadas, enquanto o numero de analfabetos no Brasil era grande.

Dessa maneira, forma-se uma estrutura política de governo perante os imigrantes, com autoridade; o poder vai sendo estruturado na sociedade e a violência a partir do momento que impede a livre relação e organização das comunidades estrangeiras.

No discurso proferido em 10 de novembro de 1939, Vargas limita as ações de imigrantes no país, como se pode perceber. Em outros discursos relaciona a política demográfica como transformadora do Brasil em uma unidade em todos os aspectos, ou seja, a nacionalização dos imigrantes e seus descendentes.

"Para bem esclarecer a idéia, devo dizer-vos que o Brasil, politicamente, é uma unidade. Todos falam a mesma língua, todos têm a mesma tradição histórica e todos seriam capazes de se sacrificar pela defesa de seu território.” (VARGAS, 1943, p. 285)

Com essa idéia de unificação através da língua objetivavam a uniformização dos saberes escolares e da formação do cidadão nacional através do uso e da aprendizagem da língua nacional no ensino. A legislação começou a enfatizar o ensino da língua nacional em todas as escolas do Paraná desde 1900 até 1938. Enfatiza a educação como uma forma poderosa a ser utilizada como instrumento para fortalecer a economia, a estrutura moral e cívica brasileira.

Comparando com a constituição de 10 de Novembro de 1937, não se faz citação à mudança nas escolas no país, apenas moldando o cidadão no caráter moral e cívico através da educação, como prescreve a constituição de 1937: 
Art. 128 - A arte, a ciência e o ensino são livres à iniciativa individual e a de associações ou pessoas coletivas públicas e particulares.

É dever do Estado contribuir, direta e indiretamente, para o estímulo e desenvolvimento de umas e, de outro, favorecendo ou fundando instituições artísticas, científicas e de ensino.

Art. 130 - O ensino primário é obrigatório e gratuito. A gratuidade, porém, não exclui o dever de solidariedade dos menos para com os mais necessitados; assim, por ocasião da matrícula, será exigida aos que não alegarem, ou notoriamente não puderem alegar escassez de recursos, uma contribuição módica e mensal para a caixa escolar.

Art. 131 - A educação física, o ensino cívico e o de trabalhos manuais serão obrigatórios em todas as escolas primárias, normais e secundárias, não podendo nenhuma escola de qualquer desses graus ser autorizada ou reconhecida sem que satisfaça aquela exigência.

Art. 132 - O Estado fundará instituições ou dará o seu auxílio e proteção às fundadas por associações civis, tendo umas; e outras por fim organizar para a juventude períodos de trabalho anual nos campos e oficinas, assim como promover-lhe a disciplina moral e o adestramento físico, de maneira a preparála ao cumprimento, dos seus deveres para com a economia e a defesa da Nação.

Percebemos, nos artigos dessa lei, a responsabilidade que o Estado assume perante a educação, a importância da saúde dos alunos com a preocupação n as aulas de Educação Física, o bom caráter e civismo que deveriam aprender e a preocupação com as escolas rurais, onde havia o maior número de escolas étnicas.

As escolas étnicas desse período não se enquadravam na proposta de educação de Getúlio Vargas, nem em todos os quesitos proposto pela lei; como na etnia alemã a cultura de origem era enfatizada nas aulas até mesmo com professores que ensinavam apenas em alemão e com material didático trazido da Alemanha, o que representava um problema para as politicas nacionalistas.

No Decreto federal 406, de 1938, Getúlio Vergas nacionaliza compulsoriamente todas as escolas do Brasil e marca o fechamento das escolas étnicas. A inclusão dos alunos de escolas étnicas para escolas públicas dá-se no que se pode observar nos dados como: "Em 1932 havia no Brasil 27.662 escolas primárias, com 2.071.437 alunos; e em 1945 já havia 44.479 escolas, com 3.548.409 alunos. (RELATÓRIO DE GOVERNO 1937 a 1942).

Alem de repressão nas escolas e nas ruas, como podemos analisar no depoimento da descendente alemã LK que nasceu em 21/06/1954, relata a vida de seu pai que veio com a família e um grupo de alemães para o Brasil por volta de 1929/1930, indo primeiramente para Santa Catarina em uma colônia onde hoje é chamada de Krauel. JK aos 12 anos estudava na escola feita pelos colonos e aprendiam apenas em alemão; porém, devido ao trabalho árduo na agricultura, sua saúde ficou debilitada o que forçou a interrupção nos estudos.

Quando tinha aproximadamente 20 anos de idade, saiu da colônia com a família e veio para Curitiba onde trabalhavam com a produção de leite. Durante o período de 1937/1938 a maioria dos fregueses era do centro de Curitiba e a família morava no bairro Boqueirão. Certo dia, ao ir levar o leite e parar no posto fiscal (parada obrigatória para chegar ao centro da cidade), o pai de JK 
encontrou um colega e conversou com ele no dialeto alemão. O fiscal, ao escutar, perguntou-lhe se não sabia que era proibido falar em alemão. JK então pergunta ao fiscal com qual terno ele saia para passear, o fiscal responde: “com o meu, óbvio”. Então JK responde dizendo que ele fala com a língua que sua mãe lhe deu e o senhor de graças a Deus que fala português, saindo rapidamente com sua carroça, pois sabia que poderia ser preso. Ao retornar para casa fez um caminho diferente passando pela região onde é hoje o bairro Novo Mundo, com medo de haver bloqueio de fiscais na Rua Marechal Floriano Peixoto que era o principal caminho para ir ao bairro Boqueirão. Ao chegar em casa os vizinhos o avisaram que realmente houve um bloqueio fiscal e por um bom período teve que mandar seu irmão entregar o leite no centro de Curitiba.

Esse relato demonstra como a repressão foi intensa na cidade de Curitiba e o constrangimento sofrido pelos alemães e seus descendentes; o poder legítimo do Estado com dominação estabelecida pela autoridade, além da dominação legal amparada por leis e pela burocracia, que é assegurado pelas normas não transgredidas e poder tradicional pelo fato do poder ser imposto pelo Estado. (WEBER, 1982)

As propagandas sobre cultura brasileira, moralismo e civismo, imagem de Getúlio Vargas e obrigatoriedades impostas nas escolas modificam a educação com um caráter extremamente nacionalista. Como consta no Relatório de Governo de 1932 a 1939:

"Durante o ano foram condignamente comemoradas todas as datas nacionais, principalmente o Dia da Pátria e o cincoentenário da Proclamação da República, com imponestes desfiles escolares.” ( RELATÓRIO DE GOVERNO, 1938, p. 55)

Medidas como proibição da língua estrangeira nas escolas e repressão foram aumentando com fiscalização militar podendo até vir à prisão quem não falasse português.

O governo brasileiro tomou medidas até certo ponto drásticas para acabar com os quistos formados nas zonas de colonização alemã foram praticadas inúmeras arbitrariedades e até violências contra colonos de origem alemã. (WILHELM, 2008)

Enfatizar a lei no âmbito educacional aliando-se com o militarismo proporcionou ao Estado Novo a idéia de que a escola também serve de defesa ao governo que agrega valores morais, econômicos e políticos. Com intuito de empregar a ordem nacional, a educação seria o melhor alvo a atingir a política de nacionalização.

\section{A NACIONALIZAÇÃO NAS ESCOLAS}

O Brasil não é inglês nem alemão. É um país soberano que faz respeitar as suas leis e defende os seus interesses. O Brasil é brasileiro. Agora, esta população, de origem colonial, que há 
tantos anos exerce a sua atividade no seio da terra, constituída de filhos e netos dos primitivos povoadores, é brasileira (...). (VARGAS, 1943)

Nesse discurso de Vargas percebe-se a obrigatoriedade do descendente em ser brasileiro patriota no país que escolhera para viver ou aqui chegara por falta de escolha. Segundo Bhabha (1998) a legitimação da produção de conhecimentos do colonizador é através da degeneração da origem racial, local, auxiliando assim a governabilidade, ou o exercício de poder.

Após 1938, nas escolas a mitificação da imagem de Vargas começou a fazer parte do cotidiano das crianças, com fotografias, cartilhas, filmes de curta metragem, entre outros; uniformizou o ensino com livros e professores todos brasileiros natos; instituiu a obrigatoriedade da disciplina Educação Moral e Cívica, e as escolas deviam participar de desfiles, paradas e manifestações ao patriotismo.

Os professores deveriam criar atividades para intensificar nas crianças o espírito nacional patriota. As escolas eram fiscalizadas pelo Departamento de Educação se estavam cumprindo com as obrigatoriedades implementadas referentes ao ensino da língua portuguesa e ao culto à imagem de Vargas. As ações pedagógicas dentro da escola agem com violência simbólica, toda ação pedagógica $(A P)$ é objetivamente uma violência simbólica enquanto imposição, por um poder arbitrário, de um arbitrário cultural. (BOURDIEU, 1970).

A AP é objetivamente uma violência simbólica, num segundo sentido, na medida em que a delimitação objetivamente implicada no fato de impor e de inculcar certas significações, convencionadas, pela seleção e a exclusão que lhe é correlativa, como dignas de ser reproduzidas por uma $A P$, re-produz (no duplo sentido do termo) a seleção arbitrária que um grupo ou uma classe opera objetivamente em e por seu arbitrário cultural. (BOURDIEU, 1970, p. 22)

Devido a resistências de algumas escolas étnicas a continuar lecionando a língua de origem, no Paraná criam-se novas escolas públicas, eliminando as escolas étnicas e instituições estrangeiras, como relata Manoel Ribas nos Relatórios de Governo de 1937 a 1949:

Ensino Primário geral: Unidades escolares: Em 1932, 1.136 e em 1942, atingiu a 1.966 unidades. Grupos Escolares: Em 1932, 50 e 3m 1942, atingiu a 87. Professorado: o numero de professores que era em 1932 de 1.816 apresenta em 1942 o numero de 3.587. Matriculas: o numero de matriculas que era de 63.895em 1932, atingiu em 1942 a 123.776 alunos. Freqüência: Em 1932 apresentou em media 38. 735 e em 1942 alcançou a cifra de 75. 025. (RELATÓRIOS DE GOVERNO, 1937 a 1942, p. 15)

A escola também é responsável pela transmissão da cultura, dos saberes socialmente organizados, da seleção dos conteúdos escolares, à luz do Estado Novo, tornou-se um aparelho de propaganda e endeusamento do Governo de Getúlio. (LANE, 1981) 
É provável, por um efeito de inércia cultural, que continuarmos tomando o sistema escolar como um fator de mobilidade social, segundo a ideologia da escola libertadora quando, ao contrário tudo tende a mostrar que ele é um dos fatores mais eficazes de conservação social, pois fornece a aparência de legitimidade as desigualdades sociais, e sanciona a herança cultural e o dom social tratado como dom natural. (BOURDIEU, 1998, p. 41)

Essa percepção do espaço num sistema social cria uma simbologia cultural mantida pela escola, pois a educação caracteriza um período histórico-social, reflete a necessidade de um grupo e um local. As idéias, a cultura, a religião e, principalmente, a língua dentro de uma etnia, permite a interpretação do outro, fornecendo uma maior interação.

Relatos de imigrantes e descendentes que viveram durante o período do Estado Novo elucidam como foi o processo de nacionalização para os alemães. Como o descente curitibano HPS, nasceu em 07/10/1930, relata que até seus sete anos de idade falava apenas o alemão em casa, devido sua mãe ser uma imigrante alemã. E apenas no primário, no Colégio Santa Maria, aprendeu a falar português. Disse não sentir dificuldades em aprender a falar português mas se incomodava com o preconceito que sofria nas ruas. Lembra também das retaliações contra pessoas que falassem em alemão, da existência de um posto fiscal que havia no bairro Boqueirão e também do dia da destruição do colégio alemão Deutsche Schule, no centro da cidade de Curitiba, onde hoje fica a praça intitulada 19 de Dezembro.

A destruição de um espaço físico, principalmente escolar, garante ao Estado o poder legitimo perante a etnia alemã, uma escola tradicional alemã situada em Curitiba, com seu fechamento e após a destruição garante a violência simbólica aos alemães e descendentes que moravam em Curitiba ou estudavam na escola. Uma violência sem coerção física; porém se torna uma violência moral e quebra de um signo cultural. A autoridade legitima as mensagens transmitidas que são recebidas e interiorizadas, podendo ser entendido como uma violência simbólica que é estabelecida no momento em que se hierarquiza as propagandas e as proibições do uso da lingua e cultura estrangeira. (BOURDIEU, 2000)

LK, filha de JK, já havia comentado anteriormente ter estudado em escolas alemãs; teve o primeiro contato em português com alguns vizinhos. Fez a pré-escola em alemão no Colégio Erasto Gaertner (em Curitiba, bairro Boqueirão) e quando foi ao primário aprendeu a falar português, pois mudou para uma escola pública devido a condições financeiras da família; porém, em casa, falava apenas o alemão, pois seu pai JK não aceitava falar português. E quando os filhos falavam a língua portuguesa ele fingia não entender; dessa forma, LK conservou a língua alemã e hoje tornou-se professora de alemão.

Percebemos que a escola étnica era particular e ministrava apenas em alemão. A senhora entrevistada aprendeu a falar português apenas na escola pública e a resistência da família em se adequar à nacionalização enfatiza a relação do processo de identidade étnica. 
Já o descendente alemão CH nasceu em Joinvile - Santa Catarina em 01/04/1921; ainda bebe foi para a cidade de Rio Negro - Santa Catarina onde estudou no grupo escolar Barão De Antonina, escola pública onde cursou o primário. Antes de entrar na escola falava em casa apenas o alemão e foi muito difícil aprender português. A mãe veio da Alemanha e não sabia falar português; não conseguia ajudar os filhos nas lições escolares. $\mathrm{CH}$ relatou a dificuldade de seu convívio com as outras crianças brasileiras pelo preconceito que sofria por ser alemão.

Quando jovem, CH foi morar em Curitiba e estudou pouco tempo na escola alemã Deutsche Schule, citada anteriormente; lembra da proibição de falar alemão; do dia do fechamento da escola e da tristeza de professores e funcionários. O fechamento da escola e a difícil vivência em Curitiba demonstra o constrangimento sofrido pelos alemães e seus descendentes durante esse período histórico.

A imigrante alemã AF nasceu na Sibéria em 25/11/1929, foi para a Alemanha e depois veio para o Brasil com aproximadamente seis anos de idade. Fixaram-se na região serrana de Santa Catarina estabelecendo uma colônia. Ao completar sete anos, matriculou-se na escola mesmo contra a vontade do pai. Na escola aprendiam em alemão com professores também imigrantes vindos da Alemanha.

AF escrevia o alemão em letra gótica e relata como foi difícil aprender a língua latina. Permaneceu na colônia até 1940 e depois veio para Curitiba; aqui as escolas ensinavam apenas em português; afirma que, infelizmente, devido ao processo de nacionalização não pode continuar os estudos, pois não conseguia aprender português. A imposição de uma nova língua foi difícil e impossibilitou sua formação educacional.

As mudanças que ocorrem num âmbito educacional expressam os ideais ou necessidades de um Estado, quando este assume funções que proporcionem tais mudanças como o processo de nacionalização. Não era interessante criar apenas uma disciplina que pudesse colocar em prática os ideais nacionalistas do Estado Novo, mas era papel da escola proporcionar isso, não esquecendo que para Vargas se tratava de uma educação moral e cívica.

\section{A LEGITIMAÇÃo DA NACIONALIDAdE COMO VIOLÊNCIA E VIOLÊNCIA SIMBÓLICA}

Com esse novo sentimento nacional patriótico a ser formado, a política do Estado Novo faz a escola cumprir a formação idealizadora do Estado. O estudante deveria ser patriota nacional, valorizar a pátria com símbolos, através das bandeiras, dos hinos, das celebrações cívicas e produzindo textos glorificando a imagem de Vargas com já citado anteriormente. 
Esse sentimento nacionalista passa a ser socialmente construído pela classe que detém o poder através das simbologias e legitimando seu caráter através das relações de comunicação, onde se gera a violência simbólica.

O interesse de grupos é legitimado pela educação ideologizada, estabelecendo como algo natural. Essa naturalização da nacionalidade é a forma de criar o habitus ${ }^{2}$ para o imigrante alemão, mesmo sendo forçado a integrar-se à cultura local.

O habitus do imigrante é gerado pelo pensamento, pela ação, percepção, pelas leis e fiscalização entre a estrutura que é o Estado, a autoridade e os imigrantes. Dessa maneira integrando o imigrante alemão, entre outras etnias ao campo $^{3}$, nesse caso a um novo país nacionalista, através de fatores históricos e sociais, pela educação, a nacionalização e o patriotismo.

Entendemos violência como destituir ou despojar alguém ou alguma coisa; e simbologia é algo de dificil percepção (ODALIA, 1993, p. 146.). Por isso, a violência simbólica, o poder simbólico é um poder invisível exercido com a cumplicidade dos que sofrem e exercem, mesmo quando quem sofre de maneira inconsciente.

O poder simbólico, poder subordinado, é uma forma transformada; quer dizer,
irreconhecível, transfigurada e legitimada, das outras formas de poder: só se pode passar
para além da alternativa dos modelos energéticos que descrevem as relações sociais com
relações de força e dos modelos cibernéticos que fazem delas relações de comunicação, na
condição de se descreverem as leis de transformação que regem a transmutação das
diferentes espécies de capital em capital simbólico e, em especial, o trabalho de
dissimulação e de transfiguração (numa palavra, de eufemenização) que garante uma
verdadeira transubstanciação das relações de força fazendo ignorar-reconheçer a violência
que elas se encarregam objectivamente e transformando-as assim em poder simbólico,
capaz de produzir efeitos reais sem dispêndio aparente de energia. (BOURDIEU, 2010, p.
15.)

Quando se utiliza a educação ou as escolas para difundir pensamentos políticos e idéias, o Estado novo detem o monopólio da violência simbólica legítima.

Através das escolas, o Estado transfere a violência simbólica para com os alemães e ou, descendentes, entre outras etnias. Sendo essa violência imposta e legitimada por quem sofre pois reproduz uma nova cultura que deve ser interiorizada. Quem sofre violência simbólica vê a imposição de uma nova cultura como algo inevitável.

\footnotetext{
${ }^{2}$ habitus: (...) a noção de habitus exprime sobretudo a recusa a toda uma serie de alternativas nas quais a ciência social se encerrou, a da consciência (ou do sujeito) e do inconsciente, a do finalismo e do mecanismo (...) como indica a palavra, é um conhecimento adquirido, e tambem um haver, um capital (...) o habitus, a hexis, indica a posição incorporada, quase postural-, mas sim de um agente em ação (...).

${ }^{3}$ campo: (...) a dificuldade que é particular à aplicação deste modo de pensamento às coisas do mundo social provém da ruptura com a percepção comum do mundo social por este exigida. Assim, para contruir realmente a noçao de campo, foi preciso passar para além da primeira tentativa de análise do - campo intelectual- como universo relativamente autónomo de relações específicas: com efeito, as relações imidiatamente visiveis entre os agentes envolvidos na vida intelectual (...) em vez de ser a transferência que está na origem da construção do objecto- como quando de vai buscar a outro universo, de preferência prestigio, etnologia, linguistica ou economia, uma noção descontextualizada, simples metáfora com função puramente emblemática- é a contrução so objecto que exige a transferência e a fundamenta: assim tratando de analisar os usos sociais da lingua, a ruptura com a noção vaga e vazia de "situação".
} 
Sendo esse poder simbólico repassado através da escola, da educação, a cultura dominante juntamente com o poder tradicional e legal proporciona a perpetuação de uma nova concepção de cultura, no caso da nacionalização, uma cultura brasileira, patriota e ditatorial. (WEBER, 1982)

Os constrangimentos ocorridos na escola, como relataram os entrevistados, de alemães e seus descendentes, a maioria mudando de escola, ou até mesmo desistindo de estudar demonstra como o poder simbolico é construído pela produção e reprodução de crença, cria uma nova ordem imposta pela Estado, legitimada pelas ideologias sustentadas pelas leis. (BOURDIEU, 2010)

\section{REFERÊNCIAS}

ABECK, H. A colaboração germânica no Paraná nos últimos 50 anos: 1929-1979. Curitiba: Fundação Cultural de Curitiba, 1980.

BHABHA, H. K. O local da cultura. Belo Horizonte: Ed. UFMG, 1998.

BOURDIEU, P. O poder simbólico. 13 ed. Rio de Janeiro: Bertrand Brasil, 2010.

BRASIL. As Constituições dos estados e da República. Rio de Janeiro: Imprensa Nacional, 1937.

FUGMANN, W. Os alemães no Paraná. Ponta Grossa: Editora UEPG, 2008.

HOBSBAWN, E; RANGER, T. A invenção das tradições. Rio de Janeiro: Paz e Terra, 1984.

KREUTZ, L. Um professor paroquial. Porto Alegre: Edufrgs; Florianópolis:EdUFSC; Caxias do Sul: EDUCS, 1991.

LANE, S. T. M.; CODO, W. Psicologia social: o homem em movimento. 13. ed. São Paulo: Brasiliense, 1994.

ODÁLIA, N. O que é violência. São Paulo: Brasiliense, 1991.

PARANÁ. Decreto n. 1.874 de 29/07/1932. Regimento Interno das Escolas.

PARANÁ. Relatório de Governo, Realizações do Governo de Manoel Ribas. (1937-1942).

Curitiba: DEAP.

PARANÁ. Relatório de Governo, Realizações do Governo de Manoel Ribas. (1932-1939).

Curitiba: DEAP.

PARANÁ. Inspector Geral de Ensino. 1920.

POUTIGANT, P. e STREIFF-FENART, J. As teorias da etnicidade. São Paulo: Fundação Editora da UNESP, 1998 
RAMBO, A .B. Nacionalidade e cidadania. In Os alemães no Sul do Brasil. Canoas: Ed. ULBRA, 1994. 45.

RENK, V. A Educação dos imigrantes alemães católicos em Curitiba. Curitiba: Ed. Champagnat, 2001

REZENDE, J. T. Paraná, espaço e memória: diversos olhares históricos geográficos. 21. ed. Curitiba: Editora Bagozzi. 2005.

SAUSSURE, F. Escritos de Linguística Geral. São Paulo: Cultrix, 2004.

TEIXEIRA, V. M. Histórias de Curitiba. Curitiba: FCC, 2008.

VARGAS, G. As Diretrizes da Nova Política do Brasil. Empresa Gráfica da "Revista dos Tribunais" Ltda. Rio de Janeiro, 1943.

VARGAS, G. A nova política do Brasil I: da aliança liberal as realizações do primeiro ano de governo. 1930/1931. Rio de janeiro: Editora livraria Olympio, 1930.

WACHOWICZ, R. C. História do Paraná. 10. ed. Curitiba: [s.n.], 2002.

WEBER, M. Ensaios de sociologia. 5. ed. Rio de Janeiro: Guanabara Koogan, 1982.

. História do Paraná. Curitiba: Imprensa Oficial do Paraná, 2001.

. 1. ${ }^{\circ}$ Centenário da emancipação política do Paraná. 1853-1953. Edição do Governo do

Paraná. Diretor-secretario Adherbal Stresser. 